\title{
Documento
}

\section{Grupos de Estudos Interdisciplinares do IEA}

Um dos mecanismos de funcionamento do IEA mais intensamente articulados, desde sua criação, e a formação de equipes interdisciplinares, integradas por pesquisadores da USP, com a colaboração de colegas de outros centros universitários, que atuam tanto no sentido da abordagem acadêmica de temas em larga duração, como com a perspectıva de média ou curta permanência, intervindo em problemáticas mais conjunturais. Esses Grupos de Estudo e de Trabalho cumprem uma das principais funções do Instituto, a de estimular a discussão e o aprofundamento da compreensão de temas relevantes da contemporaneidade científica e cultural do País, no interior da USP*.

Organizados entre novembro de 1986 e dezembro de 1987, os Grupos abordam os seguintes temas:

a) Economia da Biotecnologia;

b) Lógica e Fulosofia da Ciência;

c) Política Crentífica e Tecnológica;

d) O Psíquico nos Territorios do Social;

e) Museus e Unıversidade;

f) Educação e Constituinte.

\section{ECONOMIA DA BIOTECNOLOGIA}

O Grupo de Estudos sobre Economia da Biotecnologia formou-se em fevereiro de 1987, inicialmente denominado Grupo de Biotecnologia e sob a coordenação do prof. Hernan Chaimovich. Posteriormente, decidiu-se pela criação de um grupo dedicado especialmente aos aspectos econômicos da biotecnologia, reunindo professores da Comissto de Apoio à Biotecnologia da USP (CAB) e especialistas convidados do IPT, FEA-USP e do CNPq. As suas atividades centram-se na avaliação do impacto econômico da biotecnologia moderna, bem como no estudo de alternativas de política científica e tecnológica aplicáveis ao desenvolvimento dos setores geradores e usuários de biotecnologias no Brasil. Este Grupo é, no momento, coordenado pelo prof. Carlos Alberto Moreira-Filho.

A primeira atividade do Grupo foi promover o Simpósio sobre "O Impacto da Biotecnologia no Brasil" em colaboração com a CAB, com patrocínio da Fundação Instituto de Pesquisas Econômicas, do Núcleo de Política e Gestão em Ciência e Tecnologia da FEA-USP, e com apoio do Banco de Desenvolvimento do Estado de São Paulo-BADESP e da FIESP. Este Simpósio,

* A partir do segundo semestre de 1987, o Conselho Diretor do IEA debateu também a necessidade de se adensar determinados temas e problemas do conhecimento, aglutinando-os em áreas de concentração que merecerāo um tratamento priorizado pelo Instituto. Tais áreas säo: "Biologia Molecular" (ver artigo na pagina 93), "Ciências Ambientais", "Economia e Política" $e$ "História das Mentalidades". Essas atividades serão abordadas nesta seção no próximo número de estudos AVANÇADOS. 
realizado nos dias 8 e 9 de abril de 1987, foi aberto pelo prof. Jose Goldemberg, reitor da USP, e contou com a participação de representantes do setor privado, de institutos de pesquisa e de agências governamentais relacionados com a área. Foram discutidos temas relativos à política brasileira de biotecnologia e às oportunidades de investimento no setor. Os anais do Simpósio deverão ser publicados em breve com o apoio do BADESP.

A partir da experiência deste Simpósio, elaborou-se um projeto de pesquisa com o objetivo de caracterizar os principais mercados usuarios de biotecnologia no Brasil, avaliando o impacto econômico da biotecnologia moderna sobre eles, tendo em vista fornecer subsídios para políticas tecnologicas que atendam às especificidades dos seguintes setores: sucro-alcooleiro, papel e celulose, pecuária e sementes. Quanto ao setor de saúde, dada a peculiar relação existente entre os seus agentes, considerou-se que este tipo de estudo deveria ser feito por instituiçôes diretamente ligadas à execução de sua política nacional, embora o Grupo mantenha um banco de dados sobre este setor.

O projeto será financiado com recursos da Secretaria Especial de Biotecnologia (MCT), repassados através do CNPq. $O$ financiamento das atividades previstas deve iniciar-se em março/abril do corrente ano. Entre estas atividades, destacam-se a vinda de dois professores do Exterior, que ministrarão cursos no IEA, a realização de seminários com empresários e pesquisadores ligados aos setores em estudo, e a discussão de políticas públicas com especialistas de agências governamentais.

Entre as perspectivas de trabalho futuro do Grupo, esta a formação de um núcleo de planejamento estratégico e avaliação em ciência e tecnologia, que deverá analisar a interface entre a biotecnologia e outras áreas de tecnologia de ponta.

Atualmente, o Grupo é integrado pelos seguintes pesquisadores: Carlos Alberto Moreira Filho, Hernan Chaimovich Guralnik, Marcos Eugênio da Silva, Mitton de Abreu Campanário, Willian Cerantola e Maria Cristina B. Schmidt (assistente técnica).

\section{LOGICA E FILOSOFIA DA CIÊNCIA}

Coordenado pelo prof. Newton C. A. da Costa (Departamento de Filosofia da FFLCH-USP), o Grupo de Estudos sobre Lógica e Teoria da Ciência foi constiturdo no IEA já em novembro de 1986.

A partir do início de 1987 , foram realizados seminários semanais, alternando-se reunióes de Lógica e de Filosofia da Ciência, as sextas-feiras, em encontros realizados tanto na sede do IEA, como no Departamento de Filosofia da FFLCH. A organização das reuniōes sobre Lógica esteve a cargo dos profs. Leila Z. Puga, do Departamento de Matemática da PUC-SP, e Elias H. Alves, do Departamento de Filosofia do IFCH-UNICAMP. As reuniōes de Filosofia da 
C1ência foram organizadas pelos profs. José Chiapin e Ernesto Plantino, ambos do Departamento de Filosofia da USP. O Grupo contou, também, com atividades no campo da História da Ciência, a cargo do prof. Pablo Manconda (FFLCH).

As prnncipars lınhas de pesquisas nas quais o Grupo está engajado são as seguintes.

a) Lógica:

1) Lógicas Não-Clássicas, especialmente tópicos de Teoria de Modelos Paraconsistentes, de Lógıca Paracompleta e de Lógica Não-Reflexiva. Foram tratadas, também, questóes de Matemática Paraconsistente.

2) Lógica Deôntica: sistemas heterodoxos de Lógica Deôntica e problemas originados pela Logica Legal e Informátıca Jurídica.

3) Lógıca Intencional: investigação de sistemas heterodoxos de Logica Modal e das aplicações metamatemáticas desta última dısciplina.

b) Filosofia da Ciência:

1) Probabilidade e indução em ciêncra, especialmente 0 desenvolvımento de uma lógica indutiva baseada no concerto de verdade pragmática.

2) Aplicações da Teoria dos Modelos em Filosofia da Ciência.

3) Lógica da Aceitabilidade em Ciências Empíricas.

4) Estudo crítico da posição de B. van Fraasen em Teoria da Ciência.

c) História da Ciência:

1) Estudo da obra de Galileu e tradução de vários de seus trabalhos.

As atividades do Grupo de Lógıca e Filosofia da Ciência, que já estão resultando em artigos e intervenções científicas na área, contaram não apenas com a contribuição dos especialıstas já mencionados, como também de vários outros, tanto da USP como de outros centros. Pode-se mencionar, como exemplo, os seguintes participantes: Mineko Yamashita e Celina Abar, da PUC.SP, Décio Krause, da Universidade Federal do Paraná, Steve French, A. M. Sette e Walter Camiellı, da UNICAMP, Jair Minoru Abe, da UNESP, e Richard Epstein, dos Estados Unidos. Além disso, o Grupo pode contar ainda com a presença catalisadora do prof, Atsuyuki Suzuki, engenheiro eletrônico, matemático, especialista em inteligéncia artificial, titular da Universidade de Shizuoka, Japão. O prof. Suzuki desenvolveu suas atividades no IEA, como professor-visitante, no período de novembro de 1987 a janeiro de 1988 , sob a organização e coordenaçđo do prof. Jair Minoru Abe. 


\section{POLITICA CIENTIFICA E TECNOLOGICA}

Formado no início de 1987, e integrado por especialistas representativos de diversas áreas da USP, o Grupo de Estudos sobre Politica Cientifica e Tecnológica procurou, em um primeiro momento, recuperar a memória do tema no plano nacional e avaliar o estado atual das questôes e problemas envolvidos. Participam do Grupo, desde sua formação, os seguintes profs.: Antonio Galvão Novaes (chefe do Departamento de Transportes da Escola Politécnica-USP), Erney F. Plessmann de Camargo (vice-diretor do Instituto de Ciências Biomedicas-USP), Eunice Ribeiro Durham (chefe do Departamento de Antropologia da Faculdade de Filosofia, Letras e Ciências Humanas-USP), Flávio Fava de Moraes (ICB e diretor científico da Fundação de Amparo à Pesquisa do Estado de São Paulo-FAPESP), Gerhard Malnic (Instituto de Ciências Biomédicas-USP), Jacques Marcovitch (Faculdade de Economia e Administração-USP), Oswaldo Ubriaco Lopes (diretor do Instituto de Ciências Biomedicas-USP), Roberto Leal Lobo e Silva Filho (vice-reitor da USP) e Walter Colli (diretor do Instituto de Química-USP). Até setembro de 1987, o Grupo esteve sob a coordenação do prof. Roberto Lobo; a partir desta data, o novo coordenador é o prof. Erney Camargo.

Seguindo um cronograma regular de reuniões, sempre na sede do IEA, os integrantes do Grupo puderam trocar informações e experiências sobre sua participação direta nos mais diversos órgãos científicos nacionais e internacionais, debater problemas relativos à utilização do conhecimento científico para a geração de novas tecnologias, ao desenvolvimento acadêmico dos diferentes campos abordados, bem como sobre a questão dos custos das pesquisas em Ciência e Tecnologia e sobre o papel do Estado no fomento e subvenção dessas atividades. $O$ Grupo pode, tambem, articular posicionamentos e intervenções, além de estudar estratégias de média e longa duração.

Em 1988, o Grupo de Estudos sobre Politica Cientifica e Tecnologica contará com a participação ativa do prof. Simon Schwartzman que, como professorvisitante do IEA, desenvolverá o projeto de trabalho sobre $A$ produção de conhecimentos na Universidade. $O$ objetivo geral do projeto que será desenvolvido pelo prof. Simon, é dar início a uma série de atividades relacionadas ao estudo dos problemas que afetam as instituições de ensino superior, principalmente no que se refere à sua função central de centro de produção de conhecimentos nas ciências naturais e humanas.

\section{O PSIQUUICO NOS TERRITORIOS DO SOCIAL}

Originalmente, o Grupo foi formado com os seguintes objetivos:

a) constituir espaço de reflexão sobre a psicologia como ciência e profissão, visando a integração de disciplinas interessadas no estudo das 
relaçб̃es entre homem, seu corpo, sua sensibilidade, sua experiência do espaço social e sua apreensão do mundo vivido;

b) produzir documentos sobre as perspectivas da psicologia para o tratamento de questôes referentes ao cuidado da cidade de São Paulo.

Nas primeiras reunióes, o Grupo procurou definir temas e questôes para análise a partir do conceito de territorio do social*; que entendemos como a produçẫo de espaços particulares por indivíduos e grupos sociais em que se combinam elementos sociais e de outra natureza, alguns materiais como a paisagem, técnicas de trabalho, sexo, idade, e outros imateriais ou simbolicos como cultura, memoria, esperança ou ideologia que são veiculados em diferentes espaços geográficos.

Na medida em que procuramos compreender a clínica psicológica como um territorio do social nos termos acima descritos, dentres os elementos materiais escolhemos focalizar o trabalho do clínico (suas técnicas de trabalho) por entendê-lo como atividade que privilegia a observação do psíquico. Uma frase pode bem resumir nossa afirmação ou pergunta central: "No consultório psicológico se faz, antes de mais nada, trabalho psiquico". Como o principal instrumento do trabalho psicanalítico é a palavra, interessa-nos então a discussão do problema da linguagem e da fala, tendo em vista a escuta psicanalftica pensada como escuta do psíquico.

No que se refere aos elementos imateriais da citada definição, considerando que essa categoria tem o imaginário humano como crivo necessário, pelo qual passam os elementos que entram na composição de um território e da noção de territorialidade, interessou-nos primeiramente a elucidação do conceito de símbolo. Para tanto, tomamos como ponto de partida a teoria psicanalítica da mente e sua análise da produção de significado.

Dessa forma, na atualidade, as atividades do Grupo estão organizadas tendo em vista três planos de discussão:

1) Ánalise dos horizontes teóricos e epistemológicos da psicanálise;

2) Análise das estratégias técnicas;

3) Análise da inscrição social da clínica psicológica.

Participam do Grupo: Melany Schvartz Copit, Norberto Abreu e Silva Neto (coordenador), Sylvia Leser de Mello e Yolanda Cintrão Forghieri, docentes do Instituto de Psicologia da USP, Bento Prado de Almeida Ferraz Júnior, do Departamento de Filosofia da Universidade Federal de São Carlos, Osmyr Faria Gabbi Júnior e Zeljko Loparik, do Departamento de Filosofia da UNICAMP e Isaias Mehlson, da Sociedade Brasileira de Psicanalise.

* Cf. em Franck Auriac e Roger Brunet (ed.), Espaces, Jeux et Enjeux. Paris, Fayard, 1986. Particularmente os artigos de Yves Barel, "Le Social et Ses Territoires",

p. 129-140; Claude Raffestin, "Ecogénèse Territoriale et Territorialite", p. 173-185; e

Antoine S. Bailly, "Espace et Representations Mentales", p. 159-1 70. 


\section{MUSEUS E UNIVERSIDADE}

O Grupo de Trabalho Museus e Universidade, constiturdo por pesquisadores ligados aos acervos mais representativos da USP e coordenado pelas profas Ana Mae Barbosa (ECA.USP e diretora do Museu de Arte Contemporanea-USP) e Maria Cristina Bruno (Instituto de Pré-História-USP), foi integrado ao ciclo de atividades do IEA a partir de maio de 1987. Durante o ano passado, as discussర̄es foram centradas nas questôes do relacionamento da Universidade com suas instituiçōes que mantêm acervos e das possibilidades de articulação dessas instituições entre si e com a comunidade. Visando estes objetivos, foi organizado um cronograma de reuniôes e de estudos sobre assuntos pertinentes às atıvidades desenvolvidas junto aos acervos da USP.

Especialistas de comprovada experiência em diversas áreas foram convidados para discorrer sobre o tema Museus e Patrimonio. Como resultado destas reuniōes e de avaliações do proprio Grupo, ficou claro que inexiste na USP, hoje, uma polftica cultural voltada para os acervos sob sua salvaguarda. Essa ausência impede que se equacionem problemas de conservação e preservação; que se abram possibilidades de pesquisa e de formação de pessoal especializado nas áreas museológicas e museográficas e, ainda, que se promova a sistematizị. das informaçōes sobre os acervos. Outra consequência da situação atual é a falta de um programa de criação de novos acervos, bem como de ampliação dos que já existem. As coleções abrigadas na USP sâo importantes e merecem ser preservadas. $O$ debate sobre a utilização, conservação e divulgação desse patrimônio deve ser ampliado e a comunidade universitária alertada para os graves problemas que afligem museus e departamentos que abrigam acervos.

À USP deveria caber papel preponderante de assessoria técnica e científica para a preservação de acervos espalhados pela estado, além do seu proprio. O caminho para se atingir tais objetivos passa pela melhor utilizaçâo de recursos atualmente dispersos pelos diversos museus da USP e alguns dos seus departamentos. A articulação e cooperação entre instituiçóes que dispõem de recursos técnicos e humanos viabilizaria atendimento imediato a problemas comuns a vários órgãos.

Como uma primeira tentativa neste sentido promoveremos, no ano de 1988, um exercício de articulação entre nossas instituições, através de algumas atividades conjuntas. A partir de março, daremos ińcio a uma pequena exposiçáo, de caráter itinerante, que percorrerá espaços públicos de grande circulação no campus. Com isso, pretendemos chamar a atenção da comunidade universitária para a problemática dos museus da USP, além de apresentar as possibilidades de trabalho que advêm da leitura do objeto: pesquisa, docência e divulgação. Nela, exporemos objetos representativos das principais coleçőes, assim como informaçôes sobre os museus e institutos que mantêm acervos. Numa segunda etapa, ofereceremos um curso em nível de extensấo universitária, que deverá ter inf́cio em abril próximo, sobre os acervos da USP. O programa 
do curso compreende os tópicos: histórico da incorporação dos acervos à Universidade; conceitos básicos de museologia e conservação; possibilidades de pesquisa e docência abertas pelas coleções da USP.

Por ocasiāo da próxima reunião da SBPC, no campus da USP na cidade de São Paulo, pretendemos organizar uma exposição sobre o tema: Adorno, um exercicio de interpretaçāo, escolhido por permitir a utilização de peças da maioria dos acervos da USP.

Paralelamente a estas atividades, o Grupo pretende ainda estabelecer um cronograma para discussão dos temas:Museus, Docência e Pesquisa e Museu e Educafãão.

\section{EDUCAÇÃO E CONSTITUUNNTE}

Em maio de 1987. formou-se no Instituto de Estudos Avançados um Grupo de Trabalho cuja finalidade era discutir as propostas educacionais formuladas pela Comissão de Sistematização da Assembléia Nacional Constituinte. 0 objetivo último do Grupo era intervir nos debates e no processo decisorio do Congresso, mediante propostas tópicas que refletissem o estado da questâo no interior da Universidade.

Do Grupo, coordenado pelo seu proponente, prof. Alfredo Bosi (FFLCH-USP e membro do Conselho Diretor do IEA), participaram os profs. Jose Carlos Araújo Melchior (Educação-USP), Celso de Rui Beisiegel (Educação-USP), Dermeval Saviani (PUC-SP), Moacir Gadotti (Educação-UNICAMP), Amélia Imperio Hamburger (Fisica-USP), Shigueo Watanabe (Associação dos Cientistas do Estado de Sฮ̃o Paulo) e Maria Helena Martins (Secretaria de Educação.SP).

Para informar sobre 0 andamento dos debates na Comissão de Sistematização, foi convidado a participar de uma das sessరes do Grupo de Trabalho o deputado, prof. Florestan Fernandes.

Findos os seus trabalhos, a 7 de agosto de 1987, o Grupo enviou aos constituintes o tex to seguinte, em que figuram as suas propostas. A numeração dos artigos mencionados reporta-se ao Projeto da Comissão de Sistematização (o segundo, de que foi relator o deputado Bernardo Cabral).

\section{PROPOSTAS}

\section{Manutenção integral do art. 379}

"A União aplicara, anualmente, nunca menos de dezoito por cento, e os Estados, o Distrito Federal e os Municípios, vinte e cinco por cento, no minimo, da receita resultante de impostos, inclusive a proveniente de transferências, na manutenção e desenvolvimento do ensino."

Os educadores consideram fundamental o respeito ao princípio dos percentuais fixxados no texto da Carta Magna. Trata-se de uma prática salutar, que se 
instaurou desde a Constituinte de 1934, reforçou se na de 1946 e só foi supressa na vigência da Carta de 67 , por razões tecnocráticas.

Se os constituintes propõem a obrigatoriedade e a gratuidade do ensino oficial, considerando-o dever do Estado, sujeito à ação civil quando neglicenciado, é preciso absolutamente prover a Administração Pública de meios sólidos e constantes para o cumprimento dessa obrigação.

Os constituintes dispõem agora de instrumentos legais que o povo lhes delegou, e não é admissível que abram mão deles, relegando-os aos futuros burocratas dos orçamentos federais, estaduais e municipais.

1.1. Em consequência da proposta anterior, somos favoráveis à Emenda do art. 292, apresentada pelo senador João Calmon, e assim redigida:

"E vedado:

I - vincular receita de natureza tributária a órgão, fundo ou despesa, à exceção da aplicação do que trata o art. 379".

\section{Substituição de redação}

$O$ art. 381 passaria a ser redigido da seguinte forma:

"As verbas públicas serão destinadas às escolas públicas".

Justificação: Analisando atentamente o texto do art. 381 do atual Projeto, verificamos que aí se abrem possibilidades indiscriminadas para a concessão de subsídios às escolas particulares. Em primeiro lugar, a linguagem adotada para a concessão deixa margem a futuras pressð̃es sobre os formuladores das leis ordinárias que regularão a materia. $O$ texto diz: "podendo (as verbas), nas condições da lei, ser dirigidas a escolas confessionais, filantrópicas ou comunitárias".

Se prevalecer essa redação, excessivamente aberta, é de suma conveniência encontrar uma fórmula constitucional que vincule a concessão do subsídio a algum mecanismo de controle puiblico do seu uso.

\section{Manutenção do proposto no art. $372, I$}

“. . . democratização do acesso, permanência e gestão do ensino em todos os níveis".

Parece-nos feliz a preocupação com a permanência do aluno no seus cursos: no Brasil, $87 \%$ das crianças não concluem o 10 grau; $52 \%$ só cumprem os primeiros 2 anos de escolaridade; 31.000 .000 continuam analfabetos (IBGE, 1985).

Quanto à gestão, trata-se de uma proposta de ampliar a participação da comunidade nos destinos da educação nacional.

4. Manutenção do disposto no art. 373 , parigrafos 19 e $2 \%$ :

“§ $19-0$ acesso ao ensino obrigatório e gratuito é direito público subjetivo, acionável contra o Estado mediante mandado de injunção. 
§ 20- OChefe do Executivo competente poderá ser responsabilizado por omissão, mediante ação civil pública, se não diligenciar para que todas as crianças em idade escolar, residentes no âmbito territorial de sua competência, tenham direito ao ensino fundamental obrigatório e gratuito."

Trata-se de uma conquista da sociedade civil em sua relação com o Poder Público no que se refere à execução efetiva dos dispositivos legais sobre o ensino fundamental.

5. Manutenção do disposto no art. 372, IV, completado pelo art. 373, II Ambos os dispositivos garantem o princípio geral da gratuidade do ensino público em todos os níveis, particulanzando a sua extensão obrigatória ao ensino médio oficial.

\section{Manutenção do disposto no art. 373, III, IV, VT}

Trata-se de medidas complementares excelentes que pela primeira vez recebem amparo constitucional.

"III - atendimento em creches e pré-escolas para crianças até seis anos de idade;

IV - educação gratuita em todos os níveis de ensino às pessoas portadoras de deficiência e aos superdotados, sempre que possível em classes regulares, garantida a assistência e o acompanhamento especializados;

VI - oferta de ensino noturno adequado às condições dos discentes, observada a qualidade do ensino e as situaçōes sociais do educando."

\section{Manutenção do disposto nos arts. 383 e 384}

Garantem recursos para o ensino de 19 grau e para a qualificação profissional dos trabalhadores.

"Art. 383 - As empresas comerciais, industriais e agrícolas são responsáveis pelo ensino fundamental gratuito de seus empregados e dos filhos de seus empregados a partir dos sete anos de idade, devendo para isto contribuir com o salário educação, na forma da lei.

Art. 384 - As empresas comerciais e industriais são obrigadas a assegurar a capacitação profissional dos seus trabalhadores, inclusive a aprendizagem dos menores, em cooperação com o Poder Público, com associações empresariais e trabalhistas e com sindicatos."

$\mathrm{Na}$ firme expectativa de que os srs. constituintes examinarão com cuidado as propostas acima, subscrevemo-nos, respeitosamente (seguem-se as assinaturas dos membros do Grupo de Trabalho sobre Educação e Constituinte). 